\title{
Incarceration Among Street-Involved Youth in a Canadian Study: Implications for Health and Policy Interventions
}

\author{
John D Omura ${ }^{a, b}$, Evan Wood ${ }^{a, c}$, Paul Nguyen ${ }^{a}$, Thomas Kerr ${ }^{a, c}$, and Kora DeBeck ${ }^{a, d}$ \\ aBritish Columbia Centre for Excellence in HIV/AIDS, St. Paul's Hospital, 608-1081 Burrard \\ Street, Vancouver, BC, CANADA, V6Z 1 Y6 \\ bSchool of Population and Public Health, University of British Columbia, 5804 Fairview Avenue, \\ Vancouver, BC, CANADA, V6T 1 Z3 \\ 'Department of Medicine, University of British Columbia, St. Paul's Hospital, 608-1081 Burrard \\ Street, Vancouver, BC, CANADA, V6Z 1Y6 \\ dSchool of Public Policy, Simon Fraser University, SFU Harbour Centre, 515 West Hastings \\ Street, Suite 3271, Vancouver, BC, CANADA, V6B 5K3
}

\begin{abstract}
Background-Risk factors for incarceration have been well described among adult drug using populations; however, less is known about incarceration among at-risk youth. This study examines the prevalence and correlates of incarceration among street-involved youth in a Canadian setting.
\end{abstract}

Methods-From September 2005 to May 2012, data were collected from the At-Risk Youth Study, a prospective cohort of street-involved youth aged $14-26$ who use illicit drugs.

Generalized estimating equation (GEE) logistic regression was used to identify factors associated with recent incarceration defined as incarceration in the previous six months.

Results-Among 1019 participants, 362 (36\%) reported having been recently incarcerated during the study period. In multivariate GEE analysis, homelessness (adjusted odds ratio [AOR]= $1.60)$, daily crystal methamphetamine use $(\mathrm{AOR}=1.56)$, public injecting $(\mathrm{AOR}=1.33)$, drug dealing $(\mathrm{AOR}=1.48)$ and being a victim of violence $(\mathrm{AOR}=1.68)$ were independently associated with incarceration (all $p<0.05$ ). Conversely, female gender (AOR=0.48), lesbian, gay, bisexual, transgender or two-spirited (LGBTT) identification $(\mathrm{AOR}=0.47)$ and increasing age of first hard drug use $(\mathrm{AOR}=0.96)$ were negatively associated with incarceration (all $p<0.05)$.

Conclusion-Incarceration was common among our study sample. Youth who were homeless, used crystal methamphetamine, and engaged in risky behaviors including public injection and drug dealing were significantly more likely to have been recently incarcerated. Structural

(C) 2013 Elsevier B.V. All rights reserved

Send correspondence to: Kora DeBeck, PhD BC Centre for Excellence in HIV/AIDS 608-1081 Burrard Street, Vancouver, B.C. CANADA V6Z 1Y6 Tel: 1 (604) 806-9044 uhri-kd@cfenet.ubc.ca.

(john@johnomura.com)

(uhri-ew@cfenet.ubc.ca)

(pnguyen@cfenet.ubc.ca)

(uhri-tk@cfenet.ubc.ca)

(uhri-kd@cfenet.ubc.ca)

Publisher's Disclaimer: This is a PDF file of an unedited manuscript that has been accepted for publication. As a service to our customers we are providing this early version of the manuscript. The manuscript will undergo copyediting, typesetting, and review of the resulting proof before it is published in its final citable form. Please note that during the production process errors may be discovered which could affect the content, and all legal disclaimers that apply to the journal pertain.

Competing Interests: Authors declare no other competing interests. 
interventions including expanding addiction treatment and supportive housing for at-risk youth may help reduce criminal justice involvement among this population and associated health, social and fiscal costs.

\section{Keywords}

street youth; incarceration; drug use; homeless

\section{INTRODUCTION}

Incarceration is a well established risk factor for various negative outcomes among illicit drug using populations including: blood-borne infections such as HIV and hepatitis C (HCV) (Massoglia, 2008); relapse and persistent drug use (DeBeck et al., 2009; Galea \& Vlahov, 2002); and unemployment (Western, 2002). Although incarceration has not been demonstrated to effectively reduce problematic drug use (DeBeck et al., 2009), people who use drugs continue to be incarcerated at a staggering rate (Milloy et al., 2008). This is of particular concern as it pertains to youth as evidence suggests that placing high-risk adolescents in close proximity such as in prison facilities may inadvertently reinforce problem behavior and elevate risk for various adverse health outcomes (Dishion, McCord, \& Poulin, 1999). In light of these facts, policy makers in the United States have begun to recognize the importance of preventing the unnecessary and inappropriate incarceration of youth (U.S. House of Representatives Committee on Government Reform - Minority Staff Special Investigations Division, 2004).

Despite this awareness, the prevalence of youth incarceration in North America remains high. In 2010, the United States (US) federal juvenile justice system incarcerated approximately 70,000 youth (Sickmund, Sladky, Kang, \& Puzzanchera, 2011). In Canada, on any given day between 2010-2011 approximately 14,800 youth were housed in the correctional system (aged 12-17 years at the time of offence), representing a rate of 79 youth per 10,000 youth population (Munch, 2011). For street-involved youth specifically, survey data from a cohort study of street youth in Vancouver found that $80.5 \%$ reported having ever being incarcerated overnight or longer (Milloy, Kerr, Buxton, Montaner, \& Wood, 2009). Marginalized ethnic minority groups are also overrepresented amongst incarcerated youth. In the US, 69\% of incarcerated youth are black or Hispanic (Sickmund et al., 2011) and in Canada 26\% are of Aboriginal ancestry (Munch, 2011).

While the negative impact of incarceration on street youth is increasingly understood, risk factors for youth incarceration remain poorly studied. To date, much research on this topic has focused on offending or delinquent behaviors (Baron \& Hartnagel, 1998; Heinze, Toro, \& Urberg, 2004). Analyses that identify such behaviors in homeless and incarcerated youth are useful in demonstrating that risky behaviors appear to increase once a youth becomes immersed in street life (Thompson, Bender, Windsor, Cook, \& Williams, 2010). However, they fail to capture the broader social, behavioral and environmental context in which youth incarceration occurs. Furthermore, studies that do address these more distal factors tend to be limited by recall bias and cross-sectional designs. To better understand risk factors for incarceration amongst at-risk youth, we sought to longitudinally examine the prevalence and correlates of incarceration among a prospective cohort of street-involved youth in Vancouver, Canada.

\section{METHODS}

Data for this study was collected from the At-Risk Youth Study (ARYS), a prospective cohort of street-involved youth in Vancouver, Canada. The study has previously been 
described in detail (Wood, Stoltz, Montaner, \& Kerr, 2006). Eligibility criteria include youth between the ages of 14-26 at enrolment, who have used illicit drugs in the past 30 days and provide written informed consent. In summary, interviews are conducted at baseline and semi-annually for follow-up. Participants complete an interviewer-administered questionnaire and provide blood samples for HIV and HCV serology. The survey includes items on sociodemographic information, drug use patterns, sexual and drug-related risk behaviours, and engagement with the criminal justice system. Participants receive a $\$ 20$ CAD monetary compensation at each study visit. The ARYS cohort has been approved by the research ethics board of Providence Health Care and the University of British Columbia.

Data for this study was collected from September 2005 to May 2012. The primary outcome was reported incarceration in the past six months. This was defined as responding "yes" to the question "Have you been in detention, prison or jail in the last 6 months?" The comparison group was youth who reported no incarceration in the last six months.

Explanatory variables of interest included socio-demographic data including: age (per year older); gender (male vs. female); sexual orientation (lesbian, gay, bisexual, transgender, two-spirit (LGBTT) vs. heterosexual); Caucasian ethnicity (yes vs. no); homelessness, defined as having no fixed address, sleeping on the street, couch surfing, or staying in a shelter or hostel at some point in the previous six months (yes vs. no); and residence in Vancouver's drug use epicenter at some point in the previous six months, which is a welldescribed and defined area of the city referred to as the 'Downtown Eastside' (DTES) (yes vs. no). Substance use variables referring to behaviours in the previous six months included: daily crystal methamphetamine use, injection or non-injection (yes vs. no); daily crack cocaine smoking (yes vs. no); daily cocaine use, injection or non-injection (yes vs. no); daily heroin use, injection or non-injection (yes vs. no); any injection drug use (yes vs. no); daily marijuana use (yes vs. no); and heavy alcohol use, defined for females as $\geq$ four drinks in one day in the last week or $\geq$ seven drinks containing alcohol per week and for males as $\geq$ five drinks in one day in the last week or $\geq$ fourteen drinks containing alcohol per week (yes vs. no). Risk factors referring to behaviours in the previous six months included: public injection, defined as injecting drugs in public environments including streets, public lavatories, alleys, parks, parking lots, abandoned buildings, and other public settings (any vs. never); syringe sharing, defined as having lent a used rig to someone else or fixed with a syringe that had already been used by someone else (yes vs. no); unprotected sex, defined as vaginal or anal sex without using a condom (yes vs. no); sex work, defined as having received money, gifts, food, shelter, clothing or drugs in exchange for sex (yes vs. no); drug dealing, defined as selling drugs as a source of income (yes vs. no); and victim of violence, defined as having been attacked, assaulted, or suffered violence (yes vs. no). Other factors include: age of first hard drug use (per year older) which included crack cocaine, cocaine (sniffed or snorted), heroin (sniffed, snorted or smoked) or crystal methamphetamine (smoked or snorted); and methadone program use, defined as ever participating in a methadone program (yes vs. no).

Since analyses of factors potentially associated with incarceration included serial measures for each subject, we used generalized estimating equations (GEE) for binary outcomes with logic link for the analysis of correlated data. These methods determine factors associated with incarceration throughout the six year and nine month follow-up period and provide standard errors adjusted by multiple observations per person using an exchangeable correlation structure. Therefore, this analysis considered data from every participant followup visit. Missing data was addressed through the GEE estimating mechanism which uses all available pairs method for missing data from dropouts or intermittent missing. All nonmissing pairs of data are used in the estimators of the working correlation parameters. First, we used GEE bivariate analysis to determine factors associated with incarceration. To adjust 
for potential confounding, all variables that were $p<0.10$ in GEE bivariate analyses were considered in a full model. Quasilikelihood under the Independence model Criterion (QIC) statistic with a backward model selection procedure was used to screen all possible combinations of candidate variables and identify the model with the best overall fit as indicated by the lowest QIC value. Statistical analyses were performed using SAS software version 9.3 (SAS, Cary, NC). All reported $p$-values are two-sided and considered significant at $p<.05$.

\section{RESULTS}

A total of 1019 street-involved youth were enrolled in the study between September 2005 and May 2012. Among this sample, 320 (31\%) were female, 686 (67\%) were of Caucasian ethnicity, and the median age was 21 years at baseline (interquartile range $[\mathrm{IQR}]=19-23$ ). This sample contributed a total of 3347 observations. The median number of follow-up visits was 3 (IQR=1-5). The number of youth who reported having ever been incarcerated at baseline was $638(63 \%)$ and $189(19 \%)$ reported having recently been incarcerated at baseline. Over the study period, $362(35 \%)$ participants reported having been recently incarceration and overall, a total of $610(18 \%)$ observations included a report of incarceration.

The baseline characteristics of all participants stratified by self-reported incarceration in the previous six months are presented in Table 1 . The results of the bivariate and multivariate GEE analyses are presented in Table 2. In multivariate GEE analysis, factors that remained independently associated with incarceration included: homelessness (adjusted odds ratio $[\mathrm{AOR}]=1.60,95 \%$ Confidence Interval $[\mathrm{CI}]: 1.28-1.99)$, daily crystal methamphetamine use $(\mathrm{AOR}=1.56,95 \% \mathrm{CI}: 1.18-2.08)$, public injecting ( $\mathrm{AOR}=1.33,95 \% \mathrm{CI}: 1.04-1.72)$, drug dealing ( $\mathrm{AOR}=1.48,95 \% \mathrm{CI}: 1.20-1.84)$ and being a victim of violence $(\mathrm{AOR}=1.68$, $95 \%$ CI: $1.38-2.06)$. Conversely, female gender (AOR $=0.48,95 \%$ CI: $0.36-0.65)$,

LGBTT identification (AOR $=0.47,95 \%$ CI: $0.30-0.72)$ and increasing age of first hard drug use $(\mathrm{AOR}=0.96,95 \% \mathrm{CI}: 0.92-0.99)$ were negatively associated with incarceration.

\section{DISCUSSION}

In the present study, we observed a high proportion of youth who reported being in detention, prison or jail in the last six months. Factors positively and most strongly associated with incarceration included homelessness, drug dealing and being a victim of violence. Daily crystal methamphetamine use and public injecting were also independently associated with incarceration. Factors negatively and most strongly associated and thus protective from incarceration were female gender and LGBTT identification. Increasing age of first hard drug use was also independently associated with incarceration.

The frequency with which youth in our study were incarcerated is concerning, although largely consistent with prior figures (Milloy et al., 2009; Munch, 2011; Sickmund et al., 2011). Male youth are known to experience higher rates of incarceration, which was also indicated in our data (Barrett, Katsiyannis, \& Zhang, 2006). Our findings are also similar to previous studies demonstrating an association between incarceration and crystal methamphetamine use in youth (Milloy et al., 2009). This association may highlight a specific drug-use risk factor for youth incarceration, given previous links between crystal methamphetamine use and initiation of injection drug use (Wood et al., 2006). The trend towards significance of daily crack cocaine use in our study warrants further examination as an added potential drug-use risk factor for incarceration among youth. Together these findings point to opportunities to expand addiction treatment options for youth that may help reduce problematic stimulant drug use and the subsequent risk of incarceration. Given that 
increased age of first hard drug use was negatively associated with incarceration, our study also highlights that upstream prevention efforts that delay or prevent early initiation of hard drug use may reduce interactions with the criminal justice system later in life. This also stresses the importance of ensuring that age restrictions do not limit access to early addiction treatment for youth.

The strong association found in this analysis between homelessness and incarceration is consistent with existing literature and has been reported amongst incarcerated adults (Greenberg \& Rosenheck, 2008). Homelessness is also associated with injection drug use, injection initiation and high intensity drug use amongst street-involved youth, although it may be that homeless individuals are more visible to police and therefore more vulnerable to arrest and incarceration (Baron, 1999; Feng et al., 2013; E. Roy et al., 2003; É. Roy, Haley, Leclerc, Boudreau, \& Boivin, 2007). Together these findings highlight the role of housing as a determinant of youth health and reinforce the importance of supporting this at-risk population through housing efforts. (E. Roy et al., 2004). Indeed, supportive housing interventions may have the potential to prevent youth incarceration and its associated adverse effects by reducing the need for income generation (Debeck, Wood, et al., 2011), reducing high intensity drug use (Feng et al., 2013), and reducing interactions with police on streets (Ti, Wood, Shannon, Feng, \& Kerr, 2013). Moreover, since incarceration is known to impose high costs on public-sector spending (Henrichson \& Delaney, 2012; Miller, Fisher, \& Cohen, 2001), our data suggests that investments in housing to reduce youth incarceration could help minimize its fiscal burden. Although homelessness may increase vulnerability to incarceration, it is also possible that incarceration leads to homelessness. Incarceration has been shown to be a disruptive life event that can result in loss of housing and increased economic insecurity (Freudenberg, Daniels, Crum, Perkins, \& Richie, 2005; Pager, 2003). Given the established harms associated with homelessness, providing youth who exit the criminal justice system with supportive housing should be a public health priority. It is noteworthy that incarceration was also strongly associated with being a victim of violence. This further highlights the vulnerability of these youth and underscores the importance of ensuring that appropriate health and social supports are readily available.

In addition to housing, another socioeconomic risk factor linked to youth incarceration in our study was drug dealing. Drug dealing is prevalent in social environments where individuals have few legitimate means of generating income (DeBeck et al., 2007). Individuals who have been incarcerated are known to be more vulnerable to economic instability (Bushway, 1998), and prior studies demonstrate that drug dealing is a frequent source of income generation among people who use injection drugs (Kerr et al., 2008). Although law enforcement is typically the dominant response to address drug dealing, alternative interventions that are less hazardous and potentially of greater societal benefit have been identified. Specifically, one study reported that a high proportion of illicit drug users were willing to cease engaging in drug dealing, if they had options for low-threshold employment (Debeck, Wood, et al., 2011). By providing alternative methods of income generation for economically vulnerable individuals (Reif, Horgan, Ritter, \& Tompkins, 2004), interventions such as low-threshold employment may reduce engagement in drug dealing and subsequent interactions with the criminal justice system.

The identified association between incarceration and public injecting likely reflects the highrisk profile of individuals who inject in public areas (Darke, Kaye, \& Ross, 2001), and the fact that those who inject in public are more visible to police. While this may make public injectors more susceptible to incarceration, the association may also reflect the destabilizing influence of incarceration on the lives of young people (Darke et al., 2001; B. D. Marshall, Kerr, Qi, Montaner, \& Wood, 2010). 
Our finding that street-involved LGBTT youth are much less likely to experience incarceration has not been previously demonstrated. This is an optimistic finding since as a population LGBTT youth are often found to be at high risk for numerous negative health and social outcomes including incarceration (Himmelstein \& Bruckner, 2011). The exact nature of this relationship and its underlying mechanism warrants further investigation.

This study has several limitations. First, our sample was not random and therefore may not be generalizable to other populations. Second, data was collected using self reported interviews and is thus vulnerable to response bias. Given the sensitive nature of some interview questions, respondents may be inclined to report socially desirable responses leading to under reporting of stigmatizing behaviors such as illicit drug use and incarceration. As a result, our findings are likely conservative estimates. Third, given the non-randomized nature of this study, the relationships studied may be influenced by confounders not measured.

Our study demonstrates that incarceration is highly prevalent amongst street-involved youth in our setting, an important consideration given the known health and social harms associated with incarceration. This study identifies risk factors for youth incarceration, including homelessness, crystal methamphetamine use and engaging in risky behaviors such as public injection and drug dealing. These findings support the need for the expansion of youth-focused evidence-based addiction treatment options in addition to other structural interventions available regardless of age. In particular, options include supportive housing and economic empowerment through programs such as low-threshold employment. These public health oriented interventions may help this high-risk population avoid incarceration as well as mitigate its potential subsequent negative consequences.

\section{Acknowledgments}

The authors thank the study participants for their contribution to the research, as well as current and past researchers and staff. We would specifically like to thank Cody Calloy, Jennifer Matthews, Deborah Graham, Tricia Collingham, Carmen Rock, Peter Vann, Steve Kain and Sabina Dobrer for their research and administrative assistance. The study was supported by the US National Institutes of Health (R01DA028532) and the Canadian Institutes of Health Research (MOP-102742). This research was undertaken, in part, thanks to funding from the Canada Research Chairs program through a Tier 1 Canada Research Chair in Inner City Medicine which supports Dr. Evan Wood. Dr. Kora DeBeck is supported by a MSFHR/St. Paul's Hospital-Providence Health Care Career Scholar Award.

\section{REFERENCES}

Baron SW. Street Youths and Substance Use: The Role of Background, Street Lifestyle, and Economic Factors. Youth \& Society. 1999; 31(1):3-26.

Baron SW, Hartnagel TF. Street Youth and Criminal Violence. Journal of Research in Crime and Delinquency. 1998; 35(2):166-192.

Barrett, David E.; Katsiyannis, Antonis; Zhang, Dalun. Predictors of Offense Severity, Prosecution, Incarceration and Repeat Violations for Adolescent Male and Female Offenders. Journal of Child and Family Studies. 2006; 15(6):708-718.

Bushway SD. The Impact of an Arrest on the Job Stability of Young White American Men. Journal of Research in Crime and Delinquency. 1998; 35(4):454-479.

Darke S, Kaye S, Ross J. Geographical injecting locations among injecting drug users in Sydney, Australia. Addiction. 2001; 96(2):241-246. [PubMed: 11182868]

DeBeck K, Kerr T, Li K, Milloy MJ, Montaner J, Wood E. Incarceration and drug use patterns among a cohort of injection drug users. Addiction. 2009; 104(1):69-76. [PubMed: 19133890]

DeBeck K, Shannon K, Wood E, Li K, Montaner J, Kerr T. Income generating activities of people who inject drugs. Drug and Alcohol Dependence. 2007; 91(1):50-56. [PubMed: 17561355] 
DeBeck K, Wood E, Qi J, Fu E, McArthur D, Montaner J, Kerr T. Interest in low-threshold employment among people who inject illicit drugs: implications for street disorder. Int J Drug Policy. 2011; 22(5):376-384. [PubMed: 21684142]

Dishion TJ, McCord J, Poulin F. When interventions harm: Peer groups and problem behavior. American Psychologist. 1999; 54(9):755-764. [PubMed: 10510665]

Feng C, Debeck K, Kerr T, Mathias S, Montaner J, Wood E. Homelessness independently predicts injection drug use initiation among street-involved youth in a canadian setting. Journal of Adolescent Health. 2013; 52(4):499-501. [PubMed: 23299006]

Freudenberg N, Daniels J, Crum M, Perkins T, Richie BE. Coming home from jail: the social and health consequences of community reentry for women, male adolescents, and their families and communities. American Journal of Public Health. 2005; 95(10):1725-1736. [PubMed: 16186451]

Galea S, Vlahov D. Social determinants and the health of drug users: socioeconomic status, homelessness, and incarceration. Public Health Reports. 2002; 117(1):S135-S145. [PubMed: 12435837]

Greenberg GA, Rosenheck RA. Jail incarceration, homelessness and mental health: a national study. Psychiatry Services. 2008; 59(2):170-177.

Heinze HJ, Toro TA, Urberg KA. Antisocial behavior and affiliation with deviant peers. Journal of Clinical Child and Adolescent Psychology. 2004; 33(2):336-346. [PubMed: 15136198]

Henrichson, Christian; Delaney, Ruth. The Price of Prisons: What Incarceration Costs Taxpayers. Federal Sentencing Reporter. 2012; 25(1):68-80.

Himmelstein KE, Bruckner H. Criminal-justice and school sanctions against nonheterosexual youth: a national longitudinal study. Pediatrics. 2011; 127(1):49-57. [PubMed: 21135011]

Kerr T, Small W, Johnston C, Li K, Montaner JSG, Wood E. Characteristics of injection drug users who participate in drug dealing: implications for drug policy. Journal of Psychoactive Drugs. 2008; 40(2):147-152. [PubMed: 18720663]

Marshall BD, Kerr T, Qi J, Montaner JS, Wood E. Public injecting and HIV risk behaviour among street-involved youth. Drug and Alcohol Dependence. 2010; 110(3):254-258. [PubMed: 20456875]

Massoglia M. Incarceration as exposure: the prison, infectious disease, and other stress-related illnesses. Journal of Health and Social Behavior. 2008; 49(1):56-71. [PubMed: 18418985]

Miller TR, Fisher DA, Cohen MA. Costs of Juvenile Violence: Policy Implications. Pediatrics. 2001; 107(1):e3-e3. [PubMed: 11134467]

Milloy MJ, Kerr T, Buxton J, Montaner J, Wood E. Methamphetamine use and rates of incarceration among street-involved youth in a Canadian setting: a cross-sectional analysis. Subst Abuse Treat Prev Policy. 2009; 4:17. [PubMed: 19674473]

Milloy MJ, Wood Evan, Small Will, Tyndall Mark, Lai Calvin, Montaner Julio, Kerr Thomas. Incarceration experiences in a cohort of active injection drug users. Drug and Alcohol Review. 2008; 27(6):693-699. [PubMed: 19378451]

Munch, C. Youth correctional statistics in Canada, 2010/2011. 2011. Retrieved March 27, 2013, 2013, from http://www.statcan.gc.ca/pub/85-002-x/2012001/article/11716-eng.htm

Pager, Devah. The Mark of a Criminal Record. American Journal of Sociology. 2003; 108(5):937-975.

Reif S, Horgan CM, Ritter GA, Tompkins CP. The impact of employment counseling on substance user treatment participation and outcomes. Substance Use and Misuse. 2004; 39(13\&14):23912424. [PubMed: 15603009]

Roy E, Haley N, Leclerc P, Cedras L, Blais L, Boivin J. Drug injection among street youths in Montreal: predictors of initiation. Journal of Urban Health. 2003; 80(1):92-105. [PubMed: 12612099]

Roy E, Haley N, Leclerc P, Sochanski B, Boudreau J, Boivin J. Mortality in a cohort of street youth in Montreal. JAMA. 2004; 292(5):569-574. [PubMed: 15292082]

Roy, Élise; Haley, Nancy; Leclerc, Pascale; Boudreau, Jean-FranÇois; Boivin, Jean-FranÇois. Risk factors for initiation into drug injection among adolescent street youth. Drugs: Education, Prevention, and Policy. 2007; 14(5):389-399. 
Sickmund, M.; Sladky, TJ.; Kang, W.; Puzzanchera, C. Easy Access to the Census of Juveniles in Residential Placement. 2011. Retrieved March 27, 2013, 2013, from http://www.ojjdp.gov/ ojstatbb/ezacjrp/

Thompson, Sanna J.; Bender, Kimberly; Windsor, Liliane; Cook, Mary S.; Williams, Travonne. Homeless Youth: Characteristics, Contributing Factors, and Service Options. Journal of Human Behavior in the Social Environment. 2010; 20(2):193-217.

Ti L, Wood E, Shannon K, Feng C, Kerr T. Police confrontations among street-involved youth in a Canadian setting. Int J Drug Policy. 2013; 24(1):46-51. [PubMed: 22883543]

U.S. House of Representatives Committee on Government Reform - Minority Staff Special Investigations Division. Incarceration of youth who are waiting for community mental health services in the United States. 2004.

Western B. The Impact of Incarceration on Wage Mobility and Inequality. American Sociology Review. 2002; 67(4):526-546.

Wood E, Stoltz JA, Montaner JS, Kerr T. Evaluating methamphetamine use and risks of injection initiation among street youth: the ARYS study. Harm Reduct J. 2006; 3:18. [PubMed: 16723029] 


\section{Table 1}

Characteristics of study sample at baseline stratified by reported incarceration in the last six months $(n=1019)$.

\begin{tabular}{|c|c|c|c|c|}
\hline \multirow[b]{2}{*}{ Characteristic } & \multicolumn{4}{|c|}{ Incarcerated in the last 6 months at baseline } \\
\hline & Yes $n=189$ & No $n=830$ & OR $(95 \%$ CI $)$ & $p$-value \\
\hline Median age (IQR) & $22(20-24)$ & $21(19-23)$ & $1.05(0.99-1.12)$ & 0.086 \\
\hline \multicolumn{5}{|l|}{ Gender, $\mathbf{n}(\%)$} \\
\hline Female & $42(22.2)$ & $278(33.5)$ & $0.57(0.39-0.82)$ & 0.003 \\
\hline Male & $147(77.8)$ & $552(66.5)$ & & \\
\hline \multicolumn{5}{|c|}{ Sexual Orientation, n (\%) } \\
\hline LGBTT & $15(7.9)$ & $149(18.0)$ & $0.39(0.23-0.69)$ & $<0.001$ \\
\hline Heterosexual & $174(92.1)$ & $681(82.0)$ & & \\
\hline \multicolumn{5}{|c|}{ Caucasian ethnicity, n (\%) } \\
\hline Yes & $128(67.7)$ & $558(67.2)$ & $1.02(0.73-1.43)$ & 0.896 \\
\hline No & $61(32.3)$ & $272(32.8)$ & & \\
\hline \multicolumn{5}{|c|}{ Dropped out of high school, n (\%) } \\
\hline Yes & $152(80.4)$ & $616(74.2)$ & $1.43(0.96-2.11)$ & 0.074 \\
\hline No & 37 (19.6) & $214(25.8)$ & & \\
\hline \multicolumn{5}{|l|}{ Homeless $^{a}, \mathbf{n}(\%)$} \\
\hline Yes & $154(81.5)$ & $589(71.0)$ & $1.80(1.21-2.68)$ & 0.003 \\
\hline No & $35(18.5)$ & $241(29.0)$ & & \\
\hline \multicolumn{5}{|c|}{ Living in DTES ${ }^{a}, \mathrm{n}(\%)$} \\
\hline Yes & $53(28.0)$ & $231(27.8)$ & $1.01(0.71-1.44)$ & 0.953 \\
\hline No & $136(72.0)$ & $599(72.2)$ & & \\
\hline \multicolumn{5}{|c|}{ Heavy alcohol use ${ }^{b}, \mathbf{n}(\%)$} \\
\hline Yes & $66(34.9)$ & $311(37.5)$ & $0.90(0.64-1.25)$ & 0.512 \\
\hline No & $123(65.1)$ & $519(62.5)$ & & \\
\hline \multicolumn{5}{|c|}{ Daily marijuana use $^{a}, \mathbf{n}(\%)$} \\
\hline Yes & 94 (49.7) & $401(48.3)$ & $1.06(0.77-1.45)$ & 0.724 \\
\hline No & $95(50.3)$ & $429(51.7)$ & & \\
\hline \multicolumn{5}{|c|}{ Daily crystal methamphetamine use ${ }^{a, c}, \mathbf{n}(\%)$} \\
\hline Yes & $30(15.9)$ & $102(12.3)$ & $1.35(0.87-2.09)$ & 0.185 \\
\hline No & $159(84.1)$ & $728(87.7)$ & & \\
\hline \multicolumn{5}{|c|}{ Daily crack smoking ${ }^{a}, \mathrm{n}(\%)$} \\
\hline Yes & $51(27.0)$ & $127(15.3)$ & $2.05(1.41-2.97)$ & $<0.001$ \\
\hline No & $138(73.0)$ & $703(84.7)$ & & \\
\hline \multicolumn{5}{|c|}{ Daily cocaine use ${ }^{a, c}, \mathbf{n}(\%)$} \\
\hline Yes & $8(4.2)$ & $34(4.1)$ & $1.03(0.47-2.27)$ & 0.932 \\
\hline No & $181(95.8)$ & $796(95.9)$ & & \\
\hline
\end{tabular}




\begin{tabular}{|c|c|c|c|c|}
\hline \multirow[b]{2}{*}{ Characteristic } & \multicolumn{3}{|c|}{ Incarcerated in the last 6 months at baseline } & \multirow[b]{2}{*}{$p$-value } \\
\hline & Yes $n=189$ & No $n=830$ & OR $(95 \% \mathrm{CI})$ & \\
\hline Yes & $35(18.5)$ & $91(11.0)$ & $1.85(1.20-2.83)$ & 0.004 \\
\hline No & $154(81.5)$ & $739(89.0)$ & & \\
\hline \multicolumn{5}{|c|}{ Injection drug use ${ }^{a}, \mathbf{n}(\%)$} \\
\hline Yes & $67(35.5)$ & $231(27.8)$ & $1.42(1.02-1.99)$ & 0.038 \\
\hline No & $122(64.6)$ & $599(72.2)$ & & \\
\hline \multicolumn{5}{|c|}{ Median age of first hard drug use (IQR) } \\
\hline & $15(13-16)$ & $15(14-17)$ & $0.94(0.88-0.99)$ & 0.030 \\
\hline \multicolumn{5}{|c|}{ Methadone program, n (\%) } \\
\hline Yes & $22(11.6)$ & $54(6.5)$ & $1.89(1.12-3.19)$ & 0.015 \\
\hline No & $167(88.4)$ & $776(93.5)$ & & \\
\hline \multicolumn{5}{|c|}{ Public injection $^{a}, \mathrm{n}(\%)$} \\
\hline Yes & $57(30.2)$ & $166(20.0)$ & $1.73(1.21-2.46)$ & 0.002 \\
\hline No & $132(69.8)$ & $664(80.0)$ & & \\
\hline \multicolumn{5}{|c|}{ Shared syringes ${ }^{a}, \mathbf{n}(\%)$} \\
\hline Yes & $23(12.2)$ & $60(7.2)$ & $1.78(1.07-2.96)$ & 0.025 \\
\hline No & $166(87.8)$ & $770(92.8)$ & & \\
\hline \multicolumn{5}{|c|}{ Unprotected sex $^{a}, \mathbf{n}(\%)$} \\
\hline Yes & $112(59.3)$ & $455(54.8)$ & $1.20(0.87-1.65)$ & 0.268 \\
\hline No & 77 (40.7) & $375(45.2)$ & & \\
\hline \multicolumn{5}{|c|}{ Sex work ${ }^{a}, \mathbf{n}(\%)$} \\
\hline Yes & $23(12.2)$ & $78(9.4)$ & $1.34(0.82-2.19)$ & 0.250 \\
\hline No & $166(87.8)$ & $752(90.6)$ & & \\
\hline \multicolumn{5}{|c|}{ Drug dealing ${ }^{a}, \mathbf{n}(\%)$} \\
\hline Yes & $122(64.5)$ & $416(50.1)$ & $1.81(1.31-2.52)$ & $<0.001$ \\
\hline No & $67(35.5)$ & $414(49.9)$ & & \\
\hline \multicolumn{5}{|c|}{ Victim of violence $^{a}, \mathbf{n}(\%)$} \\
\hline Yes & $106(56.1)$ & $348(58.1)$ & $1.77(1.29-2.43)$ & $<0.001$ \\
\hline No & $83(43.9)$ & $482(41.9)$ & & \\
\hline \multicolumn{5}{|c|}{${ }^{a}$ Denotes activities in the previous six months } \\
\hline
\end{tabular}


Table 2

Univariate and multivariate GEE analysis of factors associated with incarceration among street-involved youth in Vancouver $(n=1019)$.

\begin{tabular}{|c|c|c|c|c|}
\hline \multirow[b]{2}{*}{ Characteristic } & \multicolumn{2}{|l|}{ Unadjusted } & \multicolumn{2}{|l|}{ Adjusted } \\
\hline & OR $(95 \% \mathrm{CI})$ & p-value & $\operatorname{AOR}(95 \% \mathrm{CI})$ & p-value \\
\hline \multicolumn{5}{|l|}{ Age } \\
\hline Per year older & $1.06(1.01-1.11)$ & 0.013 & & \\
\hline \multicolumn{5}{|l|}{ Gender } \\
\hline Female vs. male & $0.42(0.31-0.55)$ & $<0.001$ & $0.48(0.36-0.65)$ & $<0.001$ \\
\hline \multicolumn{5}{|l|}{ Sexual orientation } \\
\hline LGBTT vs. heterosexual & $0.44(0.29-0.67)$ & $<0.001$ & $0.47(0.30-0.72)$ & $<0.001$ \\
\hline \multicolumn{5}{|l|}{ Caucasian ethnicity } \\
\hline Yes vs. No & $0.90(0.71-1.14)$ & 0.391 & & \\
\hline \multicolumn{5}{|l|}{ Dropped out of high school } \\
\hline Yes vs. No & $1.43(1.09-1.89)$ & 0.011 & $1.30(0.97-1.75)$ & 0.084 \\
\hline \multicolumn{5}{|l|}{ Homeless $^{a}$} \\
\hline Yes vs. No & $2.02(1.65-2.47)$ & $<0.001$ & $1.60(1.28-1.99)$ & $<0.001$ \\
\hline \multicolumn{5}{|l|}{ Living in DTES $^{a}$} \\
\hline Yes vs. No & $1.20(0.98-1.48)$ & 0.085 & & \\
\hline \multicolumn{5}{|l|}{ Heavy alcohol use ${ }^{b}$} \\
\hline Yes vs. No & $1.12(0.92-1.37)$ & 0.270 & & \\
\hline \multicolumn{5}{|l|}{ Daily marijuana use ${ }^{a}$} \\
\hline Yes vs. No & $1.13(0.92-1.38)$ & 0.250 & & \\
\hline \multicolumn{5}{|c|}{ Daily crystal methamphetamine use ${ }^{a, c}$} \\
\hline Yes vs. No & $1.69(1.31-2.20)$ & $<0.001$ & $1.56(1.18-2.08)$ & 0.002 \\
\hline \multicolumn{5}{|l|}{ Daily crack smoking ${ }^{a}$} \\
\hline Yes vs. No & $1.59(1.24-2.04)$ & $<0.001$ & $1.31(1.00-1.72)$ & 0.053 \\
\hline \multicolumn{5}{|l|}{ Daily cocaine use ${ }^{c}$} \\
\hline Yes vs. No & $1.19(0.71-1.98)$ & 0.517 & & \\
\hline \multicolumn{5}{|l|}{ Daily heroin use ${ }^{a, c}$} \\
\hline Yes vs. No & $1.46(1.10-1.92)$ & 0.008 & $1.28(0.93-1.77)$ & 0.129 \\
\hline \multicolumn{5}{|l|}{ Injection drug use $^{a}$} \\
\hline Yes vs. No & $1.41(1.14-1.75)$ & 0.002 & & \\
\hline \multicolumn{5}{|l|}{ Age of first hard drug use } \\
\hline Per year older & $0.93(0.90-0.98)$ & 0.002 & $0.96(0.92-1.00)$ & 0.045 \\
\hline \multicolumn{5}{|l|}{ Methadone program } \\
\hline Yes vs. No & $1.06(0.78-1.15)$ & 0.688 & & \\
\hline \multicolumn{5}{|l|}{ Public injection ${ }^{a}$} \\
\hline Yes vs. No & $1.71(1.40-2.10)$ & $<0.001$ & $1.33(1.04-1.72)$ & 0.025 \\
\hline
\end{tabular}




\begin{tabular}{|c|c|c|c|c|}
\hline \multirow[b]{2}{*}{ Characteristic } & \multicolumn{2}{|l|}{ Unadjusted } & \multicolumn{2}{|l|}{ Adjusted } \\
\hline & OR (95\% CI) & $p$-value & $\operatorname{AOR}(95 \% \mathrm{CI})$ & p-value \\
\hline \multicolumn{5}{|c|}{ Shared syringes ${ }^{a}$} \\
\hline Yes vs. No & $1.57(1.11-2.22)$ & 0.011 & & \\
\hline \multicolumn{5}{|c|}{ Unprotected sex $^{a}$} \\
\hline Yes vs. No & $1.07(0.88-1.29)$ & 0.505 & & \\
\hline \multicolumn{5}{|l|}{ Sex work ${ }^{a}$} \\
\hline Yes vs. No & $1.11(0.79-1.57)$ & 0.536 & & \\
\hline \multicolumn{5}{|l|}{ Drug dealing $^{a}$} \\
\hline Yes vs. No & $2.00(1.64-2.43)$ & $<0.001$ & $1.48(1.20-1.84)$ & $<0.001$ \\
\hline \multicolumn{5}{|c|}{ Victim of violence $^{a}$} \\
\hline Yes vs. No & $1.83(1.52-2.20)$ & $<0.001$ & $1.68(1.38-2.06)$ & $<0.001$ \\
\hline Denotes activitie & & & & \\
\hline Denotes activiti & & & & \\
\hline
\end{tabular}

